\title{
Precursor Routes to Quaternary Intermetallics: Synthesis, Crystal Structure, and Physical Properties of Clathrate-II Cs8 $\mathrm{Na}_{16} \mathrm{Al}_{24} \mathrm{Si}_{112}$
}

\author{
Kaya Wei, Yongkwan Dong, and George S. Nolas ${ }^{*}$ \\ Department of Physics, University of South Florida, Tampa, FL 33620, USA
}

\begin{abstract}
A new quaternary clathrate-II composition, $\mathrm{Cs}_{8} \mathrm{Na}_{16} \mathrm{Al}_{24} \mathrm{Si}_{112}$, was synthesized by kinetically controlled thermal decomposition (KCTD) employing both NaSi and NaAlSi as the precursors and $\mathrm{CsCl}$ as a reactive flux. The crystal structure and composition of $\mathrm{Cs}_{8} \mathrm{Na}_{16} \mathrm{Al}_{24} \mathrm{Si}_{112}$ were investigated using both Rietveld refinement and elemental analysis, and the temperature dependent transport properties were investigated. Our results indicate that KCTD with multiple precursors is an effective method for the synthesis of multinary inorganic phases that are not easily accessible by traditional solid-state synthesis or crystal growth techniques.
\end{abstract}

Keywords: quaternary clathrate-II, crystal synthesis, transport properties

*E-mail: gnolas@usf.edu 


\section{INTRODUCTION}

Group 14 based intermetallic clathrates are of interest due to their unique structural and physical properties.[1-5] The crystal structure of binary compositions $A_{8} E_{46}$ and $A_{24} E_{136}$ (where A is an alkali, alkaline earth, or lanthanide and $\mathrm{E}$ is $\mathrm{Si}, \mathrm{Ge}$, or $\mathrm{Sn}$ ) can be thought of as a 3dimensional framework of face sharing $E_{20}$ dodecahedra and $E_{24}$ tetrakaidecahedra, and $E_{20}$ dodecahedra and $\mathrm{E}_{28}$ hexakaidecahedra, for the case of clathrate-I $\mathrm{A}_{8} \mathrm{E}_{46}$ and clathrate-II $\mathrm{A}_{24} \mathrm{E}_{136}$, respectively, inside of which the A "guest" atoms reside.[1-5] Framework substitution by triel elements (group 13) or transition metals in clathrate-I compounds is readily possible and ternary clathrate-I compounds exhibit metallic, semiconducting, superconducting, or insulating behavior depending on the substitutional atom, the occupation fraction of the group 14 atoms and vacancies, if any, on the framework.[3-6] Clathrate-I compositions have been investigated as potential thermoelectric materials in addition to a variety of other technological applications including photovoltaics, magnetocalorics and superconductivity;[1,4,7-12] however, investigations on clathrate-II compositions are rare due to the difficulty in processing clathrateII compositions in bulk form.[4] With few exceptions,[13-17] silicon clathrate-II compositions do not readily form by direct reaction of the elements. To overcome the limited access provided by conventional synthetic methods and obtain thermodynamically metastable, or otherwise difficult to access compositions, a variety of new synthetic techniques have been developed.[4] One such method, kinetically controlled thermal decomposition (KCTD), allows for the selective crystal growth of different clathrate structure types from appropriate alkali-metal precursors and reaction temperatures.[18,19] Another synthetic approach employs spark plasma sintering (SPS) whereby a pulsed DC current is the primary driver of the reaction.[20,21] A third approach 
employs a cold plate in providing the lowest possible Na vapor pressure.[22] Very recently SPS was extended for the synthesis of ternary clathrates employing more than one precursor.[23]

In this study we employ KCTD to synthesize the quaternary clathrate-II composition $\mathrm{Ca}_{8} \mathrm{Na}_{16} \mathrm{Al}_{24} \mathrm{Si}_{112}$ using $\mathrm{NaSi}$ and $\mathrm{NaAlSi}$ as precursors along with $\mathrm{CsCl}$ as the reaction flux. Although framework doped Si-based clathrate-I compositions have been investigated for thermoelectrics applications,[24-27] due to their lower weight and cost as compared to Ge-based clathrates for vehicle waste-heat recovery applications for example, this is the first report in which a clathrate-II composition is investigated with similar interests in mind. The structural and compositional characterization as well as transport properties of $\mathrm{Cs}_{8} \mathrm{Na}_{16} \mathrm{Al}_{24} \mathrm{Si}_{112}$ are discussed.

\section{EXPERIMENTAL}

All preparations were carried out in a $\mathrm{N}_{2}$-filled glove box to prevent oxidation of the elements. Elemental Al shot (99.999 \%, Alfa Aesar) and Si in lump form (99.9999 \%, Alfa Aesar) were first combined in the appropriate atomic ratio and arc melted in order to obtain an intimate mixture of the elements (and the resulting precursor phases). The resulting heterogeneous Al-Si mixture was ground into fine powder and loaded into a tungsten crucible together with $\mathrm{Na}$ $(99.95 \%$, Aldrich) in the appropriate stoichiometric ratio ( $24 \mathrm{Al}-112 \mathrm{Si}+112 \mathrm{Na} \rightarrow 24 \mathrm{NaAlSi}+$ $22 \mathrm{Na}_{4} \mathrm{Si}_{4}$ ). This crucible was then loaded into a sealed stainless steel canister, placed inside a quartz tube that was subsequently sealed under vacuum, and reacted at $923 \mathrm{~K}$ for $24 \mathrm{~h}$. The resulting product was ground thoroughly and used as the precursor in KCTD reactions.

In order to prepare the silicon clathrate-II compound with nominal composition $\mathrm{Cs}_{8} \mathrm{Na}_{16} \mathrm{Al}_{24} \mathrm{Si}_{112}$, the $\mathrm{NaSi}+\mathrm{NaAlSi}$ precursor mixture was ground together with $\mathrm{CsCl}$ (99.999\%, Acros) and synthesized by KCTD [18] at $1023 \mathrm{~K}$ for $9 \mathrm{~h}$ under a dynamic vacuum of 
$10^{-6}$ Torr to obtain the pure Si quaternary clathrate-II compound in microcrystalline form. After reaction the product was washed with ethanol and distilled water before drying in air (CAUTION: NaSi can react violently with water).[21] Consolidation of the microcrystalline powders was accomplished at $623 \mathrm{~K}$ and $400 \mathrm{MPa}$ for 10 minutes under vacuum $\left(10^{-3}\right.$ Torr $)$ by SPS using a custom-designed WC die assembly with a pulsed DC current on : off ratio of 4:1. After densification the current and pressure were released and the WC tooling was cooled to room temperature under vacuum. The density of the polycrystalline pellet was approximately $80 \%$ of the theoretical density from measurement of its dimensions and weight after polishing the surfaces of the pellet.

Powder X-ray diffraction (PXRD) data were collected with a Bruker D8 Advance diffractometer equipped with a Lynxeye detector using $\mathrm{Cu} \mathrm{K}_{\alpha}$ radiation. Structure refinements were accomplished by the Rietveld method using the GSAS suite of programs.[28,29] Energy dispersive X-ray (EDX) analysis was accomplished with an Oxford INCA X-Sight $7582 \mathrm{M}$ equipped scanning electron microscope (SEM, JEOL JSM-6390LV). PXRD and EDX were used to examine the purity and chemical composition of the specimen. Optical diffuse reflectance measurements were performed at room temperature using a JASCO V-670 UV-Vis double beam spectrophotometer equipped with a $60 \mathrm{~mm}$ diameter integrating sphere. Reflectance data were collected in the wavelength range of $200 \sim 2700 \mathrm{~nm}$. Thermal Gravimetric (TG) and Differential Thermal Analyses (DTA) measurements were carried out with a SDT Q600 (TA instruments) under $\mathrm{N}_{2}$ flow with the specimen heated from $293 \mathrm{~K}$ to $1073 \mathrm{~K}$ at a rate of $10 \mathrm{~K} / \mathrm{min}$.

The densified $\mathrm{Cs}_{8} \mathrm{Na}_{16} \mathrm{Al}_{24} \mathrm{Si}_{112}$ specimen was cut into $2 \mathrm{~mm} \times 2 \mathrm{~mm} \times 5 \mathrm{~mm}$ parallelepipeds using a wire saw for temperature dependent four-probe $\rho, S$ (gradient sweep method), and steady-state $\kappa$ measurements from $300 \mathrm{~K}$ to $12 \mathrm{~K}$. The measurements were conducted in a 
custom radiation-shielded vacuum probe with uncertainties of $4 \%, 6 \%$, and $8 \%$ for $\rho, S$, and $\kappa$ measurements, respectively.[30] Electrical contacts to the specimens were made by soldering directly to nickel-coated surfaces using standard techniques, and thermal contacts were made using Stycast epoxy. All measurements were performed perpendicular to the pressing direction.

\section{RESULTS AND DISCUSSION}

KCTD reactions of $\mathrm{NaAlSi}+\mathrm{NaSi}$ with $\mathrm{CsCl}$ were investigated at different temperatures, from $773 \mathrm{~K}$ to $1073 \mathrm{~K}$, in order to obtain the temperature for optimal yield and purity. ClathrateII forms at all temperatures, however, NaAlSi was an impurity at lower reaction temperatures (from $773 \mathrm{~K}$ to $973 \mathrm{~K}$ ), the amount of the impurity decreasing with increasing temperature. For KCTD reactions over $1073 \mathrm{~K}$ the product decomposed to $\alpha$-Si. Phase-pure $\mathrm{Cs}_{8} \mathrm{Na}_{16} \mathrm{Al}_{24} \mathrm{Si}_{112}$ was obtained at $1073 \mathrm{~K}$. Figure 1 shows the PXRD of $\mathrm{Cs}_{8} \mathrm{Na}_{16} \mathrm{Al}_{24} \mathrm{Si}_{112}$ together with those of $\mathrm{Na}_{24} \mathrm{Si}_{136}$ [18] and $\mathrm{Cs}_{8} \mathrm{Na}_{16} \mathrm{Si}_{136}$ [23] for comparison. Figure 2 shows the Rietveld analysis of $\mathrm{Cs}_{8} \mathrm{Na}_{16} \mathrm{Al}_{24} \mathrm{Si}_{112}$, the partial crystal structure is illustrated in Figure 3, and the crystallographic details are given in Table 1. The refined unit cell of $\mathrm{Cs}_{8} \mathrm{Na}_{16} \mathrm{Al}_{24} \mathrm{Si}_{112}(a=14.915(3) \AA)$ is larger than that of $\mathrm{Na}_{24} \mathrm{Si}_{136}(a=14.7121(1) \AA)$ [18] and $\mathrm{Cs}_{8} \mathrm{Na}_{16} \mathrm{Si}_{136}(a=14.7564(4) \AA)$ [23], as expected when $\mathrm{Al}$ is incorporated into the framework. $\mathrm{Cs}_{8} \mathrm{Na}_{16} \mathrm{Al}_{24} \mathrm{Si}_{112}$ is cubic (space group $F d$ $\overline{3} \mathrm{~m}$ ) with $\mathrm{Cs}$ and $\mathrm{Na}$ atoms occupying the crystallographic $8 b$ and $16 c$ sites, respectively. It is difficult to quantify the exact location of $\mathrm{Al}$ on the framework from PXRD data however our refinement results indicate $\mathrm{Al}$ to be on all three framework crystallographic sites. Site occupancy refinements for both the alkali and framework indicate full occupancy of all crystallographic sites, with good refinement results obtained for Al / Si ratio values of 0.2 / 0.8 for $8 a, 0.1 / 0.9$ for $32 e$, and 0.2 / 0.8 for $96 g$ site. The bond distances between framework atoms are very close 
to those of $\mathrm{A}_{8} \mathrm{Al}_{8} \mathrm{Si}_{38}(\mathrm{~A}=\mathrm{Na}, \mathrm{K}, \mathrm{Rb}, \mathrm{Cs})[27,31]$ and longer than those of $\mathrm{Na}_{24} \mathrm{Si}_{136}(2.3578(3) \sim$ 2.3976(6) $\AA$ ),[18] $\mathrm{Cs}_{8} \mathrm{Na}_{16} \mathrm{Si}_{136}(2.360(1) \sim 2.393(1) \AA),[23]$ and elemental $\mathrm{Si}(2.368 \AA)$. This is an indication that the larger $\mathrm{Al}$ atoms $(\mathrm{CN}=4$ and an effective ionic radius of $0.53 \AA$, as compared to $\mathrm{Si}$ with $\mathrm{CN}=4$ and an effective ionic radius of $0.40 \AA$ ) [32] are on the framework. Table 2 gives the values of the atomic coordinates, equivalent isotropic parameters $\left(\mathrm{U}_{\mathrm{eq}}\right)$ and selected bond distances are given in Tables 3. From TG/DTA analyses $\mathrm{Cs}_{8} \mathrm{Na}_{16} \mathrm{Al}_{24} \mathrm{Si}_{112}$ decomposes to $\mathrm{CsAlSiO}_{4}$ and $\alpha$-Si above $773 \mathrm{~K}$. The UV-Vis diffuse reflectance spectrum does not show any absorption edge in the entire measured range, from 200 to $2700 \mathrm{~nm}$, indicating that either the band gap is small or that the compound is metallic.

Figure 4 shows SEM images and EDX elemental mapping images of $\mathrm{Cs}_{8} \mathrm{Na}_{16} \mathrm{Al}_{24} \mathrm{Si}_{112}$. Elemental analysis (Figures 4(b) and 4(c)) of a cross section of the polycrystalline densified pellet (Figure 4(a)) shows uniform distribution of each element. The composition obtained by EDX analysis gives a $\mathrm{Cs} / \mathrm{Na} / \mathrm{Al} / \mathrm{Si}$ atomic percent ratio of 4.9(1):12.5(5):13.0(3):69.6(8) (averaging data acquisitions from eight different points on the specimen), close to the target composition $\mathrm{Cs}_{8} \mathrm{Na}_{16} \mathrm{Al}_{24} \mathrm{Si}_{112}(5: 10: 15: 70)$.

The temperature dependent $\rho, S$, and $\kappa$ are shown in Figure 5. The modulus of $S$ increases linearly with increasing temperature throughout the measured temperature range while the $\rho$ values increase with increasing temperature above $75 \mathrm{~K}$. The measured room temperature $S$ (-32 $\mu \mathrm{V} / \mathrm{K})$ is smaller than that of $\mathrm{A}_{8} \mathrm{Al}_{8} \mathrm{Si}_{38}(\mathrm{~A}=\mathrm{K}, \mathrm{Rb}, \mathrm{Cs})$ [31] but comparable to that of other $\mathrm{Al}$ containing clathrate-I compounds such as $\mathrm{Na}_{8} \mathrm{Al}_{8} \mathrm{Si}_{38}(-22 \mu \mathrm{V} / \mathrm{K}),[20] \mathrm{Ba}_{8} \mathrm{Al}_{14} \mathrm{Si}_{31}(-21 \mu \mathrm{V} / \mathrm{K})$ [33] and $\mathrm{Ba}_{8} \mathrm{Al}_{16} \mathrm{Si}_{30}(-48 \mu \mathrm{V} / \mathrm{K})$. [34] The relatively low density of our polycrystalline specimen, resulting in relatively high $\rho$ values throughout the measured temperature range, illustrates the difficulty in densifying alkali-encapsulated Si-based clathrates, as is the case for 
alkali-encapsulated Si-based clathrate-I compositions. [26,27] Although our refinement and EDX results do not allow us to quantify the aluminum content precisely, our electrical transport data suggest that the $\mathrm{Al}$ content is less than the target $\mathrm{Cs}_{8} \mathrm{Na}_{16} \mathrm{Al}_{24} \mathrm{Si}_{112}$ content. Semiconducting behavior is expected for $\mathrm{Cs}_{8} \mathrm{Na}_{16} \mathrm{Al}_{24} \mathrm{Si}_{112}$, from simple crystal chemistry arguments, however deviation from this stoichiometry will result in a metallic $S$ and $\rho$ temperature dependence, as shown in Figure 5. The measured $\kappa$ values are shown in Figure 5 and increase up to $200 \mathrm{~K}$ after which point they decrease with increasing temperature. This behavior is similar to that of $\mathrm{Cs}_{8} \mathrm{Na}_{16} \mathrm{Ge}_{136}[35]$ and $\mathrm{Na}_{24} \mathrm{Si}_{136}$,[36] however, our $\kappa$ values are much smaller than that of these two compositions. Using the measured $\rho$ values and the Wiedemann-Franz relation $\left(\kappa_{\mathrm{E}}=L_{0} \sigma T\right.$ where $L_{0}=2.45 \times 10^{-8} \mathrm{~W} \Omega \mathrm{K}^{-2}$ and $\sigma=1 / \rho$ ), the electronic contribution, $\kappa_{\mathrm{E}}$, to $\kappa$ was estimated to be relatively small.

\section{CONCLUSION}

A quaternary intermetallic silicon clathrate-II compound was synthesized by KCTD by employing a precursor that was a mixture of $\mathrm{NaSi}$ and $\mathrm{NaAlSi}$ together with the alkali metal halide $\mathrm{CsCl}$. This is the first time a clathrate-II Al-Si framework composition is reported. Structural refinement indicates full occupancy of the framework and that Cs and Na reside at the crystallographic $8 b$ and $16 c$ sites, respectively. The framework bond distances, as well as PXRD refinement and elemental analysis, indicate that $\mathrm{Al}$ atoms are present on the framework sites. Transport and solid state UV-Vis diffuse reflectance measurements show semimetallic behavior with electron conduction. Our results indicate that the KCTD synthetic method can be employed for the synthesis of multinary inorganic clathrate phases that cannot be accessible by traditional crystal growth techniques. 


\section{ACKNOWLEDGEMENTS}

We gratefully acknowledge support from the U. S. Department of Energy, Basic Energy

Sciences, Division of Materials Science and Engineering, under Award No. DE-FG0204ER46145. 
Table 1. Crystallographic details.

\begin{tabular}{|c|c|c|c|c|c|c|}
\hline \multicolumn{3}{|c|}{ Space group, $\mathrm{Z}$} & \multicolumn{2}{|c|}{$F d \overline{3} m(\# 227), 1$} & & \\
\hline \multicolumn{3}{|c|}{$\mathrm{a}, \AA$} & \multicolumn{2}{|c|}{$14.915(3)$} & & \\
\hline \multicolumn{3}{|l|}{$\mathrm{V}, \AA^{3}$} & \multicolumn{2}{|c|}{$3328(2)$} & & \\
\hline \multicolumn{3}{|c|}{ Diffractometer } & \multicolumn{2}{|c|}{ Bruker D8 Advance } & & \\
\hline \multicolumn{3}{|l|}{ Radiation } & \multicolumn{2}{|c|}{$\mathrm{Cu} \mathrm{K \alpha}(1.54056 \AA)$} & & \\
\hline \multicolumn{3}{|l|}{$\mathrm{T}(\mathrm{K})$} & \multicolumn{2}{|c|}{298} & & \\
\hline \multicolumn{3}{|c|}{$D_{\text {calc. }}, \mathrm{g} / \mathrm{cm}^{3}$} & \multicolumn{2}{|c|}{2.615} & & \\
\hline \multicolumn{3}{|c|}{$\theta$ limits, deg. } & \multicolumn{2}{|c|}{7.5 to 50} & & \\
\hline \multicolumn{3}{|c|}{ Reduced $\chi^{2}$} & \multicolumn{2}{|c|}{3.34} & & \\
\hline \multicolumn{3}{|c|}{$\mathrm{R}_{\mathrm{p}}, \mathrm{wR} \mathrm{R}_{\mathrm{p}}$} & \multicolumn{2}{|c|}{$0.0577,0.0795$} & & \\
\hline \multicolumn{2}{|c|}{ Goodness-of-fit on $\mathrm{F}^{2}$} & & \multicolumn{2}{|c|}{1.83} & & \\
\hline \multicolumn{7}{|c|}{$w R_{p}=\left(\left(\Sigma w\left(\mathrm{I}_{0}-\mathrm{I}_{\mathrm{c}}\right)^{2} / \Sigma w \mathrm{I}_{\mathrm{o}}^{2}\right)^{1 / 2}\right.$ and $\mathrm{R}_{\mathrm{p}}=\Sigma\left|\mathrm{I}_{\mathrm{o}}-\mathrm{I}_{\mathrm{c}}\right| / \Sigma \mathrm{I}_{\mathrm{o}}$} \\
\hline Atoms & $\begin{array}{l}\text { Wyckoff } \\
\text { sites }\end{array}$ & $\mathrm{x}$ & $\mathrm{y}$ & $\mathrm{z}$ & occupancy & $\mathrm{U}_{\text {iso }}$ \\
\hline $\mathrm{Cs}$ & $8 b$ & 0.3750 & 0.3750 & 0.3750 & 1 & $0.028(4)$ \\
\hline $\mathrm{Na}$ & $16 c$ & 0 & 0 & 0 & 1 & $0.040(5)$ \\
\hline Sil/Al1 & $96 g$ & $0.0670(1)$ & $0.0670(1)$ & $0.3706(2)$ & $0.8 / 0.2$ & $0.016(4)$ \\
\hline $\mathrm{Si} 2 / \mathrm{A} 12$ & $32 e$ & $0.2185(2)$ & $0.2185(2)$ & $0.2185(2)$ & $0.9 / 0.1$ & $0.005(4)$ \\
\hline $\mathrm{Si3/A13}$ & $8 a$ & 0.1250 & 0.1250 & 0.1250 & $0.8 / 0.2$ & $0.007(4)$ \\
\hline
\end{tabular}

Table 3. Selected bond distances (Å).

\begin{tabular}{llll}
\hline Cs $-\mathrm{Si} 1$ / Al1 & $3.987(3) \times 12$ & $\mathrm{Na}-\mathrm{Si} 1 / \mathrm{Al} 1$ & $3.418(2) \times 12$ \\
$\mathrm{Cs}-\mathrm{Si} 1 / \mathrm{Al} 1$ & $4.051(2) \times 12$ & $\mathrm{Na}-\mathrm{Si} 2 / \mathrm{Al} 2$ & $3.326(3) \times 6$ \\
$\mathrm{Cs}-\mathrm{Si} 2$ / Al2 & $4.043(6) \times 4$ & $\mathrm{Na}-\mathrm{Si} 3 / \mathrm{Al} 3$ & $3.229(1) \times 2$ \\
& & & \\
$\mathrm{Si} 1$ / Al1 - Si1 / Al1 & $2.398(3) \times 2$ & $\mathrm{Si} 2 / \mathrm{Al}-\mathrm{Si} 1 / \mathrm{Al} 1$ & $2.389(4) \times 3$ \\
& $2.445(4)$ & $\mathrm{Si} 2 / \mathrm{Al} 2-\mathrm{Si} 3 / \mathrm{Al} 3$ & $2.415(6)$ \\
$\mathrm{Si} 1$ / Al1 - Si2 / Al2 & $2.389(4)$ & $\mathrm{Si} 3 / \mathrm{Al} 3-\mathrm{Si} 2 / \mathrm{Al} 2$ & $2.415(6) \times 4$ \\
\hline
\end{tabular}




\section{Figure Captions}

Figure 1. PXRD pattern for $\mathrm{Cs}_{8} \mathrm{Na}_{16} \mathrm{Al}_{24} \mathrm{Si}_{112}$ compared with simulated patterns of $\mathrm{Cs}_{8} \mathrm{Na}_{16} \mathrm{Si}_{136}$ and $\mathrm{Na}_{24} \mathrm{Si}_{136}$. The red vertical line is intended to illustrate shift in the $\mathrm{Cs}_{8} \mathrm{Na}_{16} \mathrm{Al}_{24} \mathrm{Si}_{112}$ peaks relative to $\mathrm{Cs}_{8} \mathrm{Na}_{16} \mathrm{Si}_{136}$ and $\mathrm{Na}_{24} \mathrm{Si}_{136}$.

Figure 2. PXRD data for $\mathrm{Cs}_{8} \mathrm{Na}_{16} \mathrm{Al}_{24} \mathrm{Si}_{112}$ including profile fit (black cross mark), profile difference (red line), profile residuals (blue line), and Bragg positions (purple ticks) from Rietveld refinement.

Figure 3. Partial crystal structure of $\mathrm{Cs}_{8} \mathrm{Na}_{16} \mathrm{Al}_{24} \mathrm{Si}_{112}$ illustrating all the crystallographic sites and their local environments. Cs $(8 b)$ and $\mathrm{Na}(16 c)$ reside at the center of dodecahedron and hexakaidecahedron, respectively. $\mathrm{Si}$ and $\mathrm{Al}$ are on all three framework sites (8a, cyan; 32e, red; and $96 g$, blue). Atomic displacement parameters are shown for $90 \%$ probability.

Figure 4. (a) SEM image of a cross section and (b) elemental analysis from this cross sectional area with the magnified SEM image of the area represented by a red square in (a) as the inset. (c) EDS elemental mapping images of the SEM image in (a).

Figure 5. Temperature dependent (a) $\rho$ and (b) $S$, and (c) $\kappa$. 


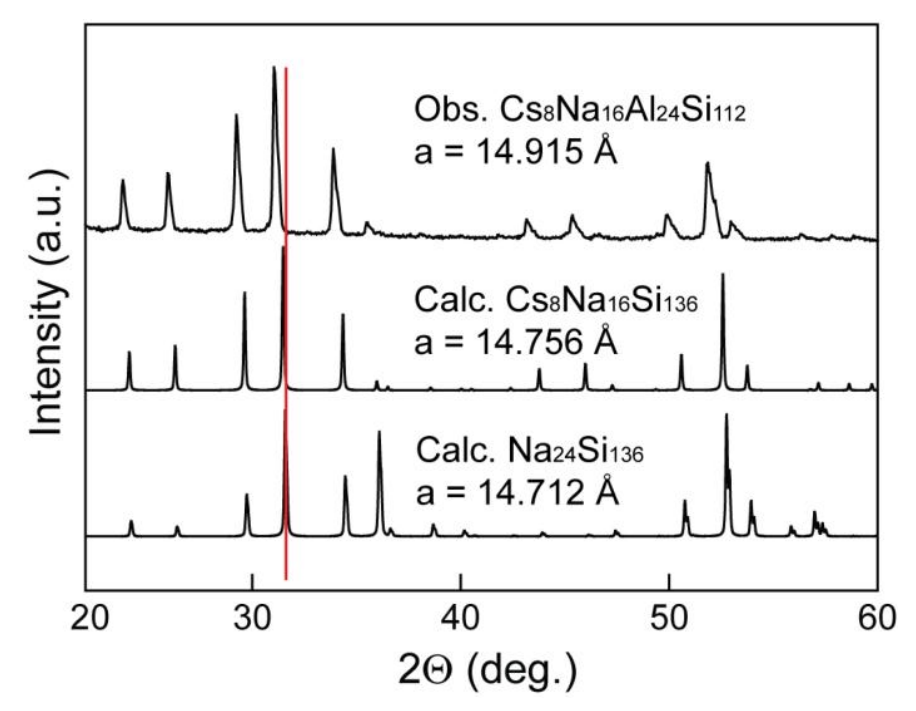

Figure 1.

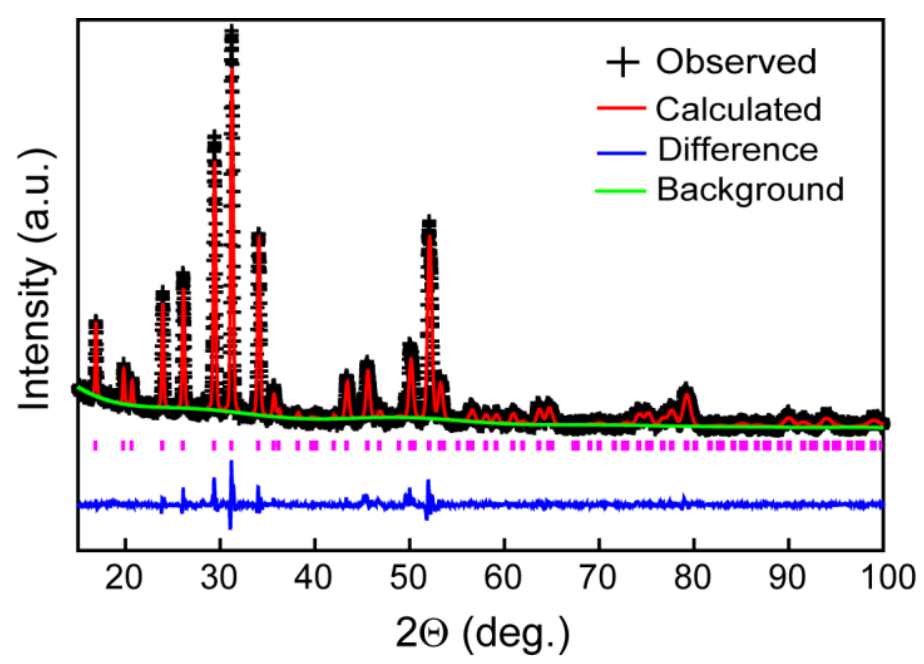

Figure 2. 


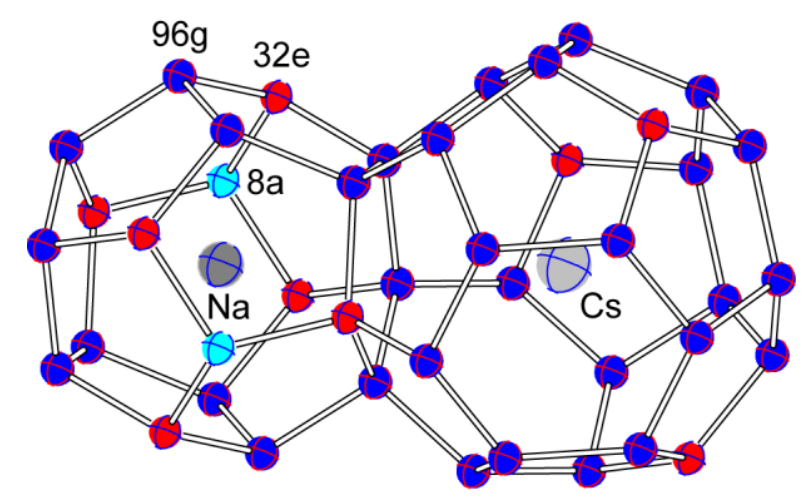

Figure 3.
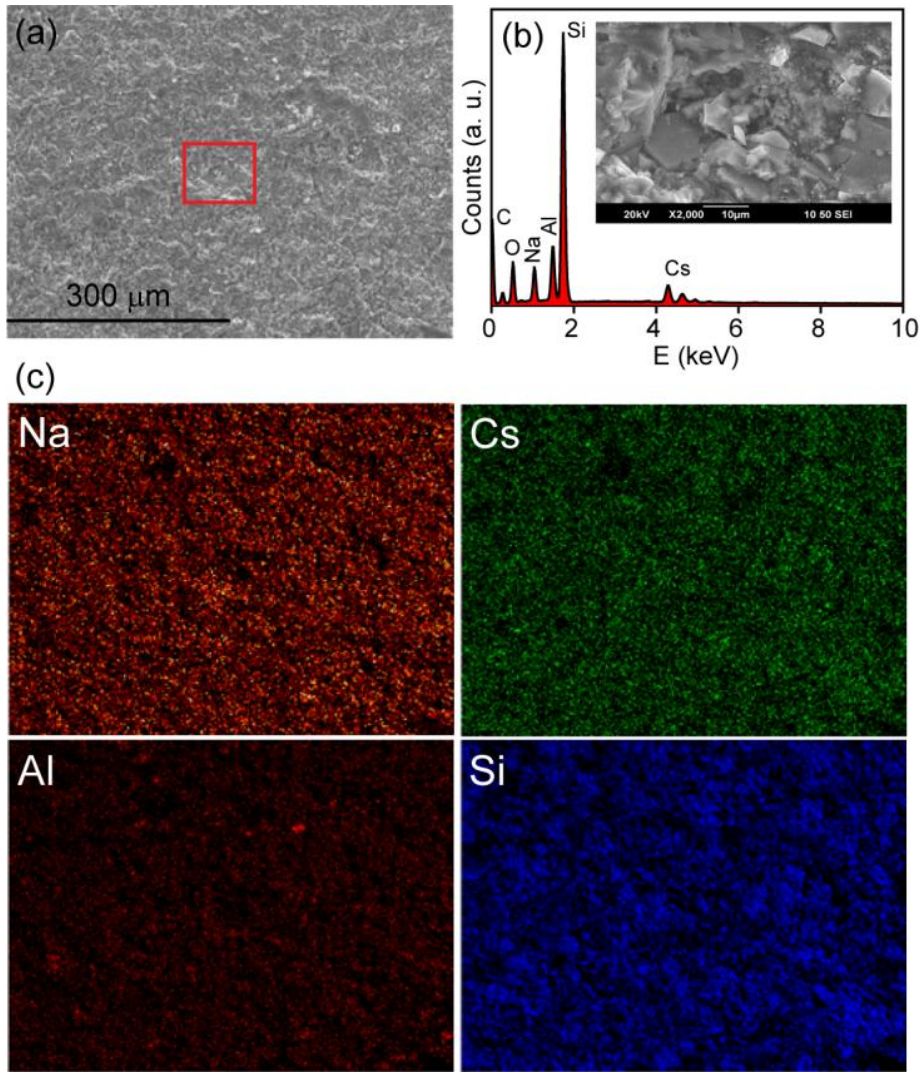

Figure 4. 


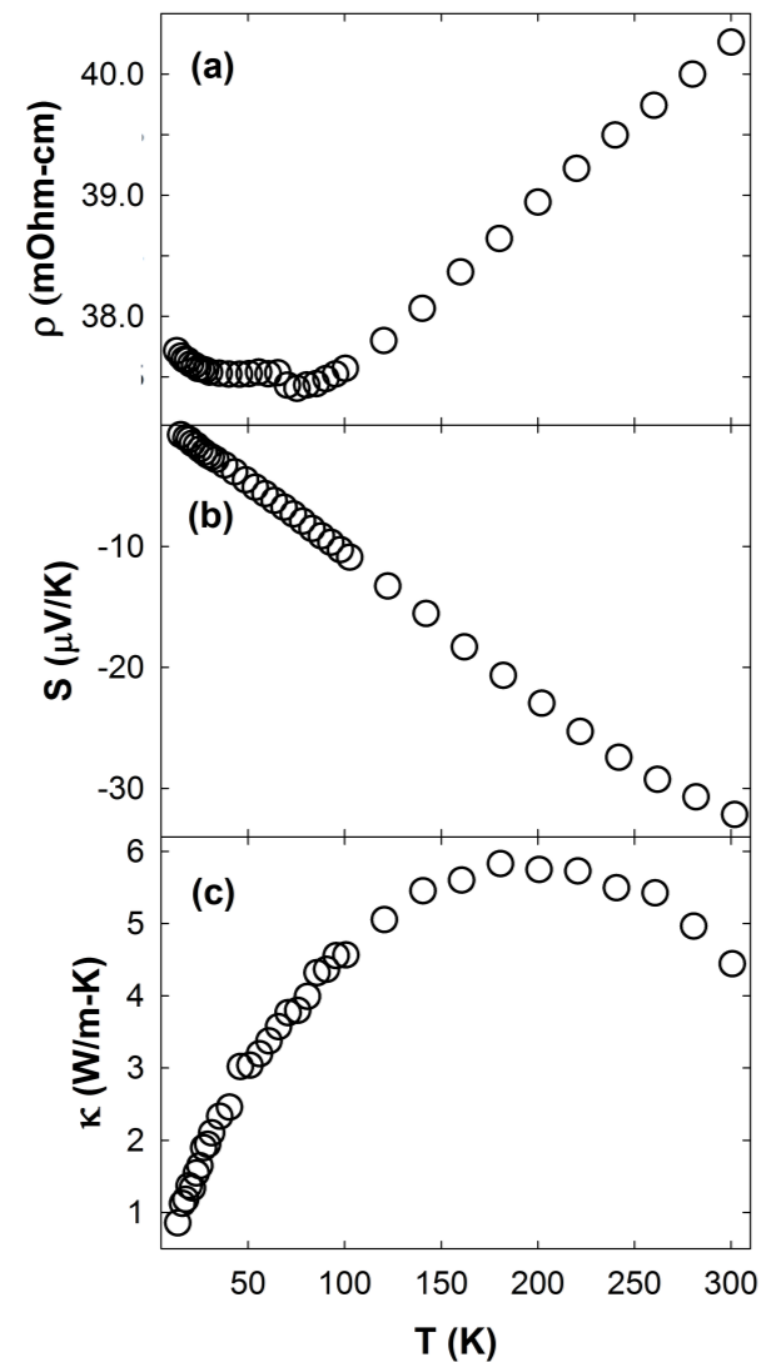

Figure 5. 


\section{REFERENCES}

(1) G.S. Nolas and G.A. Slack, American Scientist 89 (2001) 136-141.

(2) K.A. Kovnir, A.V. Shevelkov, Russ. Chem. Rev. 73 (2004) 923-938.

(3) P. Rogl, in Handbook of Thermoelectrics, D.M. Rowe, Ed. (CRC Press, Boca Raton, FL, 2006), Chapter 32.

(4) The Physics and Chemistry of Inorganic Clathrates; Nolas, G. S., Ed., Springer: New York, 2014.

(5) M. Beekman, D.T. Morelli and G.S. Nolas, Nature Communications, 14 (2015) 1182-1185.

(6) A.P. Wilkinson, C. Lind, R.A. Young, S.D. Shastri, P.L. Lee, G.S. Nolas, Chem. Mater. 14 (2002) 1300-1305.

(7) A. Chaturvedi, S. Stefanoski, M-H. Phan, G. S. Nolas, H. Srikanth, Appl. Phys. Lett. 99, (2011) 162513.

(8) A.V. Shevelkov, K.A. Kovnir, Struct. Bond. 139 (2011) 97-142.

(9) L.L. Baranowski, L.Krishna, A.D. Martinez, T. Raharjo, V. Stevanović, A.C. Tamboli, E.S. Toberer, J. Mater. Chem. C 2 (2014) 3231-3237.

(10) X. Shi, J. Yang, S. Bai, J. Yang, H. Wang, M. Chi, J.R. Salvador, W. Zhang, L. Chen, W. Wong-Ng, Adv. Funct. Mater. 20 (2010) 755-763.

(11) J. Martin, H. Wang, G.S. Nolas, Appl. Phys. Lett. 92 (2008) 222110/1-222110/3.

(12) A. Prokofiev, A. Sidorenko, K. Hradil, M. Ikeda, R. Svagera, M. Waas, H. Winkler, K. Neumaier, S. Paschen, Nature Mater. 12 (2013) 1096-1101.

(13) G.S. Nolas, C.A. Kendziora, J. Gryko, J. Dong, A. Poddar, C.W. Myles and O.F. Sakey, J. Appl. Phys. 92 (2002) 7225-7230.

(14) S. Mano, T. Onimaru, S. Yamanaka, T. Takabatake, Phys. Rev. B 84 (2011) 214101/1214101/6.

(15) M.C. Schäfer, S. Bobev, J. Am. Chem. Soc. 135 (2013) 1696-1699.

(16) M. Beekman, J.A. Kaduk, J. Gryko, W. Wong-Ng, G. S. Nolas, J. of Alloys and Comp. 470 (2009) 365-368.

(17) A.N. Mansour, M. Beekman, W. Wong-Ng, G. S. Nolas, J. of Solid State Chem. 182 (2009) 107-114.

(18) S. Stefanoski, M. Beekman, W. Wong-Ng, P. Zavalij, G.S. Nolas, Chem. Mater. 23 (2011) 1491-1495.

(19) S. Stefanoski, G.S. Nolas, Cryst. Growth Des. 11 (2011) 4533-4537.

(20) M. Beekman, M. Baitinger, H. Borrmann, W. Schnelle, K. Meier, G.S. Nolas, Y. Grin, J. Am. Chem. Soc. 131 (2009) 9642-9643. 
(21) S. Stefanoski, M.C. Blosser, G.S. Nolas, Cryst. Growth Des. 13 (2013) 195-197.

(22) L. Krishna, L.L. Baranowski, A.D. Martinez, C.A. Koh, P.C. Taylor, A.C. Tamboli, E.S. Toberer, Cryst. Eng. Comm. 16 (2014) 3940-3949.

(23) Y. Dong, G.S. Nolas, Cryst. Eng. Comm. 17 (2015) 2242-2244.

(24) V. L. Kuznetsov, L. A. Kuznetsova, A. E. Kaliazin, and D. M. Rowe, J. Appl. Phys. 87 (2000) 7871-7875.

(25) C.L. Condron, S.M. Kauzlarich and G.S. Nolas, Inorg. Chem. 46 (2007) 2556-2562.

(26) F. Sui, H. He, S. Bobev, J. Zhao, F.E. Osterloh, and S.M. Kauzlarich, Chem. Mater. 27 (2015) 2812-2820.

(27) Y. Dong, P. Chai, M. Beekman, X. Zeng, T.M. Tritt, and G.S. Nolas, Inorg. Chem. 54 (2015) 5316-5321.

(28) A.C. Larson, R.B. Von Dreele, General Structure Analysis System; Report LAUR 86-748, Los Alamos National Laboratory: Los Alamos, NM, 2004.

(29) B.H. Toby, J. Appl. Crystallogr. 34 (2001) 210-221.

(30) J. Martin, G.S. Nolas, H. Wang, J. Yang, J. Appl. Phys. 99 (2006) 044903/1-044903/5.

(31) V. Baran, A. Senyshyn, A.J. Karttunen, A. Fischer, W. Scherer, G. Raudaschl-Sieber, T.F. Fässler. Chem. Eur. J. 20 (2014) 1-13.

(32) R.D. Shannon, Acta Crystallogr. A 32 (1976) 751-767.

(33) C.L. Condron, J. Martin, G.S. Nolas, P.M.B. Piccoli, A.J. Schultz, S.M. Kauzlarich, Inorg. Chem. 45 (2006) 9381-9386.

(34) Y. Mudryk, P. Rogl, C. Paul, S. Berger, E. Bauer, G. Hilscher, C. Godart, H. Noël, J. Phys. Condens. Matter 14 (2002) 7991-8004.

(35) G.S. Nolas, D.G. Vanderveer, A.P. Wilkinson, J.L. Cohn, J. Appl. Phys. 91 (2002) 89708973.

(36) M. Beekman, W. Schnelle, H. Borrmann, M. Baitinger, Y. Grin, G.S. Nolas, Phys. Rev. Lett. 104 (2010) 018301/1-018301/4. 


\title{
For Table of Contents Use Only
}

\section{Precursor Routes to Quaternary Intermetallics: Synthesis, Crystal Structure, and Physical Properties of Clathrate-II $\mathrm{Cs}_{8} \mathbf{N a}_{16} \mathbf{A l}_{24} \mathrm{Si}_{112}$}

\author{
Kaya Wei, Yongkwan Dong, and George S. Nolas*
}

Quaternary $\mathrm{Cs}_{8} \mathrm{Na}_{16} \mathrm{Al}_{24} \mathrm{~S}_{112}$ clathrate-II was synthesized for the first time by kinetically controlled thermal decomposition (KCTD) employing a $\mathrm{NaSi}+\mathrm{NaAlSi}$ precursor mixture with $\mathrm{CsCl}$ as the reactive flux, and the structural and transport properties were investigated. Our approach demonstrates a new synthetic pathway for the synthesis of multinary inorganic compounds. This work reports the exploration of a new clathrate composition as this class of materials continues to be of interest for thermoelectrics and other energy-related applications.

*To whom correspondence should be addressed. E-mail: gnolas@usf.edu. 
For Table of Contents Use Only

Precursor Routes to Quaternary Intermetallics: Synthesis, Crystal Structure, and Physical Properties of Clathrate-II Css $\mathbf{N a}_{16} \mathbf{A l}_{24} \mathbf{S i}_{112}$

\author{
Yongkwan Dong, Kaya Wei, and George S. Nolas*
}

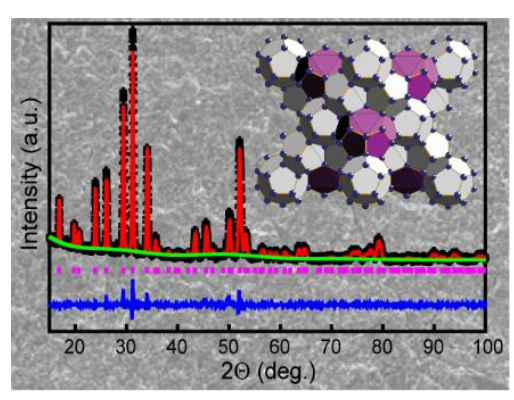

*To whom correspondence should be addressed. E-mail: gnolas@usf.edu. 